\title{
Optimized combination model and algorithm of parking guidance information configuration
}

\author{
Zhenyu Mei ${ }^{i^{*}}$ and Ye Tian ${ }^{2}$
}

\begin{abstract}
Operators of parking guidance and information (PGI) systems often have difficulty in providing the best car park availability information to drivers in periods of high demand. A new PGI configuration model based on the optimized combination method was proposed by analyzing of parking choice behavior. This article first describes a parking choice behavioral model incorporating drivers perceptions of waiting times at car parks based on PGl signs. This model was used to predict the influence of PGI signs on the overall performance of the traffic system. Then relationships were developed for estimating the arrival rates at car parks based on driver characteristics, car park attributes as well as the car park availability information displayed on PGI signs. A mathematical program was formulated to determine the optimal display PGI sign configuration to minimize total travel time. A genetic algorithm was used to identify solutions that significantly reduced queue lengths and total travel time compared with existing practices. These procedures were applied to an existing PGI system operating in Deqing Town and Xiuning City. Significant reductions in total travel time of parking vehicles with PGl being configured. This would reduce traffic congestion and lead to various environmental benefits.
\end{abstract}

Keywords: parking guidance information, parking choice, optimized display model, genetic algorithm

\section{Introduction}

Intelligent transportation systems (ITS) can significantly alleviate the problems of congestion, pollution, and accidents within an urban centre, by releasing the real-time traffic information to drivers. Parking guidance information system (PGIS) is one of ITS applications, which displays the information about the direction to and availability of parking spaces to reduce the time finding available spaces as well as the queuing time during peak period relying on the variable message signs (VMS) [1-4]. Recent advances in the development of wireless vehicular networks have become a cornerstone of ITS. Security is a fundamental issue for vehicular networks since without security protection ITS communication does not work properly $[5,6]$. For large parking lots, through Wireless sensor networks and vehicular communication, a new smart parking scheme were proposed for providing the drivers with real-time parking navigation service,

\footnotetext{
* Correspondence: meizhenyu@zju.edu.cn

'Department of Civil Engineering, Zhejiang University, Hangzhou, 310058, China

Full list of author information is available at the end of the article
}

intelligent antitheft protection, and friendly parking information dissemination [7-10].

In most large cities in China, parking guidance sign boards have been set for displaying parking information. Parking guidance signs, as a method of mass guidance strategy, can display the name, parking space occupancy, and driving direction to car parks for drivers. But whether the car park information leads to better effect, and how to depict the best car park availability information to drivers are still under research in China [11,12].

In the recent researches and applications of PGIS around the world, it is commonly used to display the same parking information for vehicles coming from different directions. Although this method can truly reflect the utilization of the parking spaces in the monitored areas, there still exists a problem that the drivers coming from different directions are likely to behave all the same with each other [13-15]. So how to determine the best availability status to display on the signs is becoming a common problem. This particularly relates to periods where demand levels are approaching capacity. Since signs are generally located some distance from car parks, PGI system

\section{里 Springer}

(C) 2011 Mei and Tian; licensee Springer. This is an Open Access article distributed under the terms of the Creative Commons Attribution License (http://creativecommons.org/licenses/by/2.0), which permits unrestricted use, distribution, and reproduction in any medium, provided the original work is properly cited. 
operators must determine when to display FULL for car parks before their utilization has reached capacity.

\section{System analyses}

When there is no parking guidance system, the driver would select the parking spaces based on his own demand and judgment. If it comes to the popular parking spaces within the urban area, drivers are likely to make the similar decisions. This situation will lead the parking demand to exceed the parking capacity. Meanwhile, too many vehicles searching for parking spaces will cause traffic congestion in peak time.

The temporal utilization of car parks is influenced by the arrival and departure rates of vehicles. Drivers' choice behavior is influenced by driver characteristics as well as the attributes of car parks and PGI signs. The optimized model of PGIS configuration is based on the real parking supply and demand conditions to display optimized parking information on VMS to influence the performance of parking system in central city. Figure 1 describes how the total travel time of vehicles is estimated based on the drivers' parking choice behavior and predicted arrival rates at car parks.

Since the optimized model of PGIS configuration considers the parking choice behavior, the following assumptions were made to provide simplistic representation of the model.

(1) All the parking spaces are off-street.

(2) There is no illegal parking.

(3) If the drivers observe the PGI sign board, they will make their parking choice at the location of the sign boards.

\section{Parking choice behavior model}

From the perspective of Microeconomics, the parking space chosen is determined by the impedance of the parking spaces. The drivers will always choose the parking space with the lowest impedance, which is related to the consumed time and cost [11,16-18]. The time consumed includes trip time $T_{\mathrm{m}}$, waiting time $T_{\mathrm{w}}$, and access time $T_{\mathrm{a}}$. The cost is mainly the parking fee $p$. The total parking utility $U$ is calculated as

$$
U\left(T_{\mathrm{m}}, T_{\mathrm{w}}, T_{\mathrm{a}}, p\right)=\alpha T_{\mathrm{m}}+\beta T_{\mathrm{w}}+\gamma T_{\mathrm{a}}+\mu p(t)+\tau_{i}
$$

where $\alpha, \beta, \gamma, \mu, \tau$ are all utility parameters. $T_{\mathrm{m}}$ is the time consumed for the in-vehicle traveling from the location of VMS to the parking space. $T_{\mathrm{w}}$ is the queuing time before entering the park. $T_{\mathrm{a}}$ is the walk time from the parking set to the destination. $p(t)$ is related to the parking price and the expected parking duration.

The length from the location of VMS to the parking space is the nearest network distance. The average speed is related to the road impedance function and can be calculated by the BPR function proposed by the U.S. Federal Highway Administration [14]. The trip time is calculated as

$$
T_{\mathrm{m}}=\frac{L_{\mathrm{m}}}{v_{\mathrm{m}}}=L_{\mathrm{m}} \frac{\prod_{i}\left[1+\omega_{i}\left(\frac{q_{i}}{C_{i}}\right)^{\varphi_{i}}\right]}{v_{0}}
$$

where $L_{\mathrm{m}}$ is the distance from the location of VMS to the parking space, $\mathrm{km} ; v_{\mathrm{m}}$ is the average speed of the vehicle, $\mathrm{km} / \mathrm{h} ; q_{\mathrm{i}}$ road traffic flow, $\mathrm{pcu} / \mathrm{h} ; C_{\mathrm{i}}$ is the road capability, pcu/h; $v_{0}$ is the free-flow speed, $\mathrm{km} / \mathrm{h} ; \omega_{\mathrm{i}}, \phi_{\mathrm{i}}$ are all model parameters; $i=1,2$ stands for motor vehicles and non-motor vehicles.

The access time refers to the walk time from the parking space to the destination. It can be calculated based on the average distance from the parking space to the activity spot and the average walk speed can be calculated by

$$
T_{\mathrm{a}}=\frac{l_{\mathrm{a}}}{v_{\mathrm{a}}}
$$

where $l_{\mathrm{a}}$ is the distance from the parking to the activity spot, $\mathrm{km} ; v_{\mathrm{a}}$ is the average walk speed, $\mathrm{km} / \mathrm{h}$.

Though there are various possibilities for parking behavior, it is always expected to choose the best (with the lowest impedance) parking space. From the view of drivers, under the normal condition of parking areas, the parking spaces with certain location, convenient service, short distance to the destination and acceptable waiting time are likely to attract more vehicles $[19,20]$.

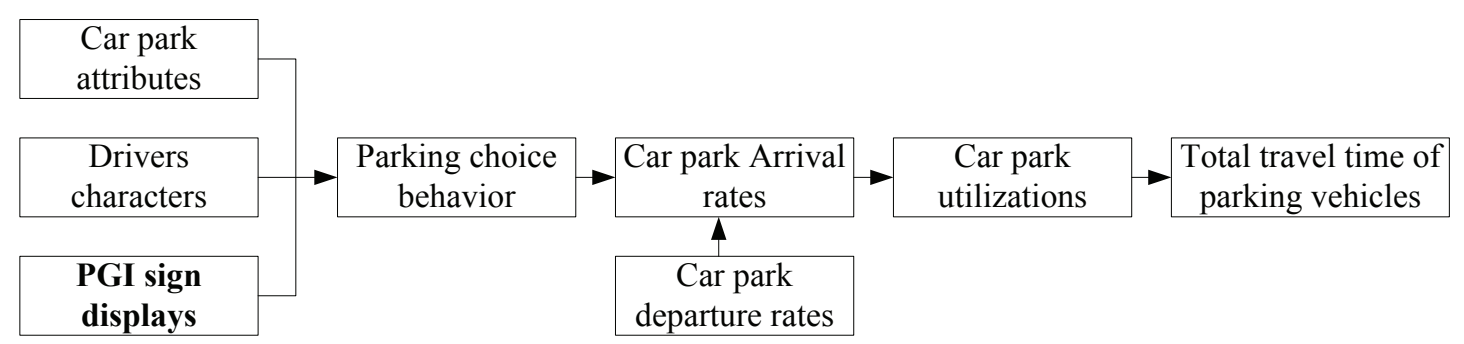

Figure 1 Parking guidance information system analysis 
A constant perceived waiting time is assumed at car parks for drivers observing the PGI signs displaying car parks to be unavailable. Drivers not observing the PGI signs are also assumed to perceive a constant waiting time at car parks having a high utilization (e.g., above 95\%). These drivers are having information regarding the actual utilization of car parks.

Thus, assuming that a set of drivers selecting parking space $j$ in zone $k$ from the location VMS $i$, the parking choice model of having observing PGI signs can be constructed as

$$
P_{i j k}=\frac{\exp \left[-\theta \cdot U_{i j k}\left(T_{\mathrm{m}}, T_{\mathrm{w}}, T_{\mathrm{a}}, p\right)\right]}{\sum_{j=1}^{J} \exp \left[-\theta \cdot U_{i j k}\left(T_{\mathrm{m}}, T_{\mathrm{w}}, T_{\mathrm{a}}, p\right)\right]}
$$

where $P_{i j k}$ is the probability to select parking space $j$ from location $i$ to destination zone $k$ with having observing PGI signs; $U_{i j k}\left(T_{\mathrm{m}}, T_{\mathrm{w}}, T_{\mathrm{a}}, p\right)$ is the utility function of parking space $j, \%$; $\theta$ is a scale parameter. Here,

$$
T_{\mathrm{W}}= \begin{cases}C, & \text { if PGI sign board displays car park } j \text { not available in }\left[S_{t}, S_{t+1}\right], \\ 0, & \text { otherwise }\end{cases}
$$

$S_{t}$ is the start of time interval $t$ and $S_{t+1}$ is the start of time interval $t+1$, where $C$ is the perceived waiting time at car park (min).

The parking choice model of having not observing PGI signs can be constructed as,

$$
P_{i j k}^{0}=\frac{\exp \left[-\theta \cdot U_{i j k}\left(T_{\mathrm{m}}, T_{\mathrm{w}}, T_{\mathrm{a}}, p\right)\right]}{\sum_{j=1}^{J} \exp \left[-\theta \cdot U_{i j k}\left(T_{\mathrm{m}}, T_{\mathrm{w}}, T_{\mathrm{a}}, p\right)\right]}
$$

where $P_{i j k}^{0}$ is the probability to select parking space $j$ from location $i$ to destination zone with having not observing PGI signs. Here,

$$
T_{\mathrm{w}}= \begin{cases}C, & \text { if } U_{j}>F, \text { at time } D_{l}, \\ 0, & \text { otherwise }\end{cases}
$$

where $U_{j}$ is the utility of car park $j$ at time $D_{l}(\%), F$ the non-observers utility threshold (\%), and $D_{l}$ is the time that the PGI display configuration for interval $l$ is determined.

\section{Parking arrivals dynamic estimation}

The model developed here assumes that the availability status of car parks displayed on the PGI signs is constant for small time intervals (e.g., 5 or $10 \mathrm{~min}$ ). The arrival of vehicles at car parks must be predicted for three separate periods (Figure 2).

During the first period, the arrival rate in park $j$ is constant and equals to the existing rate experienced when the display configuration was determined. Assume drivers make decision at the time $\mathrm{D}_{l}$, reach the PGI sign $i$ at the time $\mathrm{S}_{l}$, This rate is assumed to continue until vehicles begin arriving at car parks after observing the new configuration that has been determined. This involves determining the minimum travel time from signs to car parks.

For the second period, from the time $S_{l}+\min \left\{t_{i j}\right\}$, the arrival rate is dually influenced by the last display configuration and the determined one because of the different travel times from the signs to car parks in the network, till the time $S_{i}+\max \left\{t_{i j}\right\}$.

For the third period, from the time $S_{i}+\max \left\{t_{i j}\right\}$ to $S_{l}$ $+1+\min \left\{t_{i j}\right\}$, the arrival rate at parking lot $j$ is only influenced by the current dispay configuration. This period terminates when it is possible for vehicles to arrive at a car park after observing the next display configuration after the one to be determined.

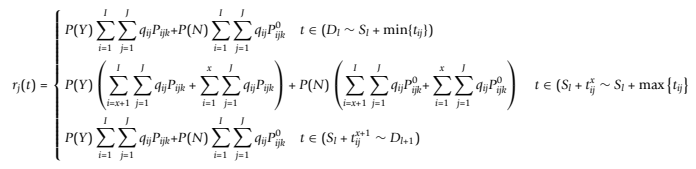

where $r_{j}(t)$ is the arrival rate of park $j, x=1,2,3 \ldots, I, P$ $(Y)$ the probability observed PGI sign board and $P(N)$ is the probability did not observe PGI sign board and $t_{i j}^{x}$ is sequenced from lesser to greater, $x=1,2, \ldots, I . q_{i j}$ is the parking flow rate from deciding node $i$ to park $j$.

Therefore, the total amount of arriving parking vehicles can be calculated as:

$$
R_{j}(t)=\int_{D_{l}}^{D_{l+t}} r_{j}(t) \mathrm{d} t
$$

\section{Parking guidance model}

To implicate the parking guidance configuration strategies, an objective function should be determined and a mathematical optimized model should be constructed. Comparing to the conventional parking without the parking guidance, the advantage of parking guidance can be shown clearly as following. The origin of the model is to get the shortest vehicle kilometers of travel (time) in urban area to get to the first choice parking space. Usually, the total travel time $T$ is easy to get and it can represent the meaning of vehicle kilometers of travel [21]. Thus, $T$ is regarded as the decision variable in this article. For parking space $j$, the objective function can be built as follow:

$$
\text { Min. } T=T_{\mathrm{m}} R_{j}(l)
$$

where $T_{\mathrm{m}}$ is the time consumed from location $i$ to parking space $j$ for vehicle $m, \min ; R_{j}(l)$ is the total amount of vehicles of park $j$ coming from location $i$ to 


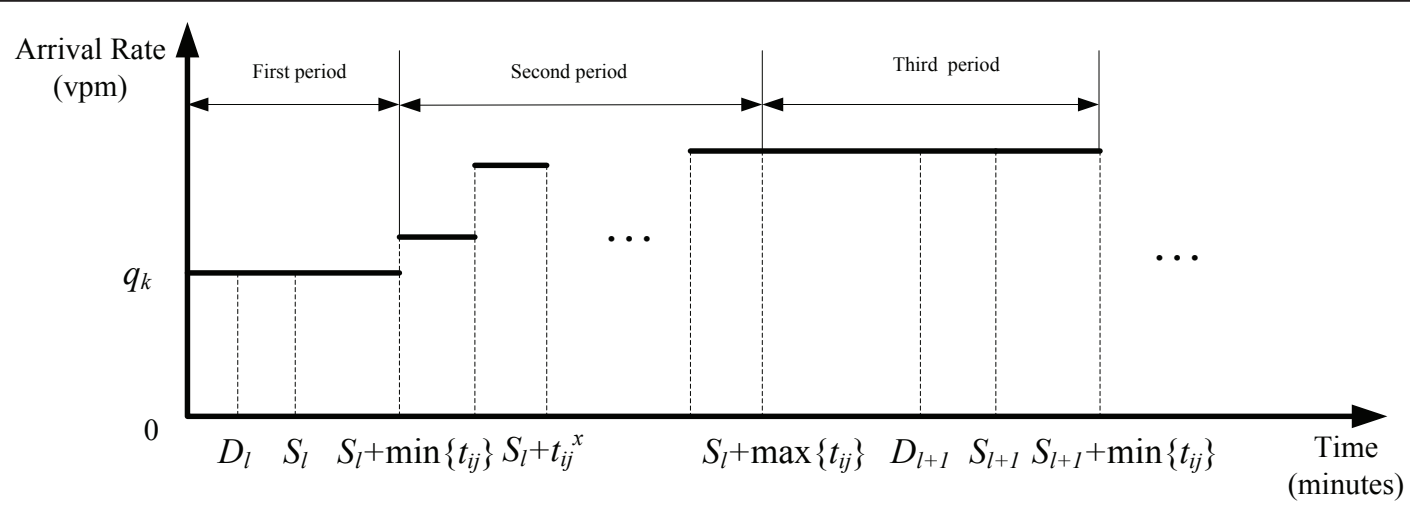

Figure 2 Parking arrival rate between $D_{l}$ and $D_{l+1}$ in park $j$.

destination zone $k$ in time $l$, veh/h; $l$ is the time interval of the status displayed on VMS, min.

The real-time utilization of parking spaces can be divided into ' $F$ ' (Full) and ' $E$ ' (Empty) where ' $F$ ' represents the parking space is full and ' $E$ ' represents the parking space is still available as well as the number of parking sets available displayed on the VMS. Considering Equations 810 , we can find that the objective function $T$ is influenced by $P_{i j k}$ directly and can influence the parking choice through the status displayed on VMS. Its nature is to get the optimized value of objective function through the configuration of the status displayed on VMS. For the status displayed on VMS in each display interval, the following 'configuration optimization method' is proposed to demonstrate how it works.

When $j$ parking spaces are available, $I$ signs display ' $\mathrm{F}$ ' or 'E' randomly. The same parking space would have different status in different zone. Thus, the final optimization results obtained through continuous iterative calculation based on the method. The constrained conditions are as follows:

$$
\delta_{i j k}=\left\{\begin{array}{l}
0: \tau_{i j k}=100 \% . \\
0: \text { depicting car park } j \text { in } k \text { distric unavailable on sign } i, \sigma_{j} \leq \tau_{i j k}<100 \% . \\
1: \text { depicting car park } j \text { in } k \text { distric available on sign } i, \sigma_{j} \leq \tau_{i j k}<100 \% . \\
1: \text { depicting car park } j \text { in } k \text { distric available on sign } i, \tau_{i j k}<\sigma_{j} .
\end{array}\right.
$$

where $\delta_{i j k}$ is a Boolean variable which represents the utilization of parking space $j$ in zone $k$ from sign $i . \tau_{i j k}$ is the utilization of car park. $\sigma_{j}$ is the threshold.

Based on this method, the availability status displayed on each VMS can be determined by Equations 10 and 11 instantaneously.

\section{Model algorithm}

If each PGI sign board displays the availability status of all parking spaces in this system, there will be $2^{I J}$ possible status combinations for each interval. Because of the large amount of possible display configurations and the complexity of the relationships, an accuracy solution procedure cannot be applied. Thus, an algorithm with a faster convergence speed and more accurate result is very necessary.

Genetic algorithm (GA) is a self-organized and adoptive artificial intelligent (AI) technology based on the simulation of Darwin's Biological Evolution Theory and Mendel's Genetic Variation/Mutation Theory. It can be classified as the configuration search and optimization method. From the eyes of overall optimization, GA does not need to calculate the partial derivative; neither does it need the continuity and differentiability of the optimized objects. Compared to the former two, every step in GA makes full use of available status to guide the search procedure, in order to pass on the good information to the offspring as well as to eliminate the bad information. Besides, GA allows more than one current result during the search time, to obtain good robustness. It can not only enhance the optimization level on numerical results but also get the approximate linear acceleration effect $[22,23]$. Thus, GA can find the optimized result in a reasonable time.

As GA works based on probability while the parking choice probability is influenced by the saturation of parking spaces, according to Equation 11, the availability status displayed on VMS during a specified time interval are coded as the chromosome:

$$
\delta_{m}=\left\{\begin{array}{c}
1: \text { depicting car park }(l / J-[l / J] \times \text { Javailable on } \operatorname{sign}([l / J]+1) \\
0: \text { depicting car park }(l / J-[l / J] \times J \text { Junavailable on } \operatorname{sign}([l / J]+1)
\end{array}(m=1,2, \cdots, I J)\right.
$$

where $[l / J]$ is an integer less than or equal to $l / J$.

Based on standard genetic algorithm (SGA) and 'configuration optimization method', procedures of mortified SGA are implemented;

1. Coding: Binary coding is the simplest coding method. Since $\delta_{\mathrm{m}}$ in Equation 12 has two values, 0 or 1, the binary coding is possible. It can make Gene Icon with low rank, short length, and high fitness to generate more offspring. This method speeds up the convergence and agrees with the principle of GA. 
Since GA cannot address the spatial solution set data, the chromosome variables $\delta_{\mathrm{m}}$ is first coded as binaries to make them the genetic string structure data in genetic space. When coding, more than one variable can be code, or all variables can be coded into one chromosome to make each variable as a part of the chromosome. To make the article compact and the presentation easy, we code $j$ parking spaces in zone $k$ as $I$ chromosomes based on the entrance number just like what Figure 3 shows. Each chromosome is a data string composed by 1 and 0 .

2. Generate initial solution set: Based on the characteristics of GA, for the fixed $\mathrm{m}(\mathrm{m}=1,2, \ldots, I J)$ VMSs' status, $H=2^{I J}$ initial solution sets are determined randomly, then $N=H$ initial population can be obtained. In the model, $N$ is determined by the number of parking spaces in the certain zone and the accuracy of solution.

3. Determination of fitness function and calculation of individual fitness: This model aims at the shortest total travel time in certain zone. The fitness function is the objective function in Equation 10.

The constrained conditions are given in Equation 11. Put $N$ initial populations into Equation 10 and the related fitness can be get.

During the calculation, the binary coded individual should be decoded as the decimal form in the search space. For example, 10100 should be decoded as 20 .

4. Population's selection and duplication: In order to select good individuals from the $N=H$ initial populations, the probability method which is direct proportional to the individual fitness is adopted. The detail procedures are as follows;

Optimize the initial population for $N$ times, get the individual fitness $f_{i}=\min \left(T_{i}\right)(I=1,2, \ldots, N)$.
- Calculate out the sum of all the individual fitness $S=\sum_{i=1}^{N} f$.

- Calculate out the percentage of the value of the individual is fitness in $\mathrm{S}$.

- Based on the aim to get the shortest total travel time, the order of selection probability $P_{i}$ as the reverse order of $f_{i} / S$ is determined, which means the one with the lowest fitness will get the highest probability to be selected out.

$\circ$ Based on the selection probability and the number of population, the duplication is conducted, which means when $\delta_{j}(j=1,2, \ldots, m)$ s selection probability is $P_{j}$, $N \times P_{j}$ individuals from duplication can be get. The population with large selection probability will get more choice to be duplicated and those with small selection probability would be eliminated. Because of duplication, the populations in mating pool reduce the average travel time in certain zone. However, no new chromosome is given birth to, leaving the fitness of the best individuals in the population unchanged.

5. Crossover: The detail procedures of crossover are as follows:

○ Pair the $\delta_{j}(j=1,2, \ldots, m)$ in the population where there are $N=m$ individuals randomly.

○ Identify the crossover probability $P_{\mathrm{c}}$, standing for the percentage of individuals which involves into crossover. For example, if $P_{c}=0.5$, then half of the population are paired and the information is exchanged. The larger $P_{\mathrm{c}}$ is the fast the exchanges are and more possible the good individuals are produced, the fast the speed of convergence is.

- Decide the crossover location in the paired individuals. The paired ones exchange part of the binary information, leaving other parts unchanged. Two new individuals are produced by crossover. Figure 4 shows how single-point crossover works.

Mutation:

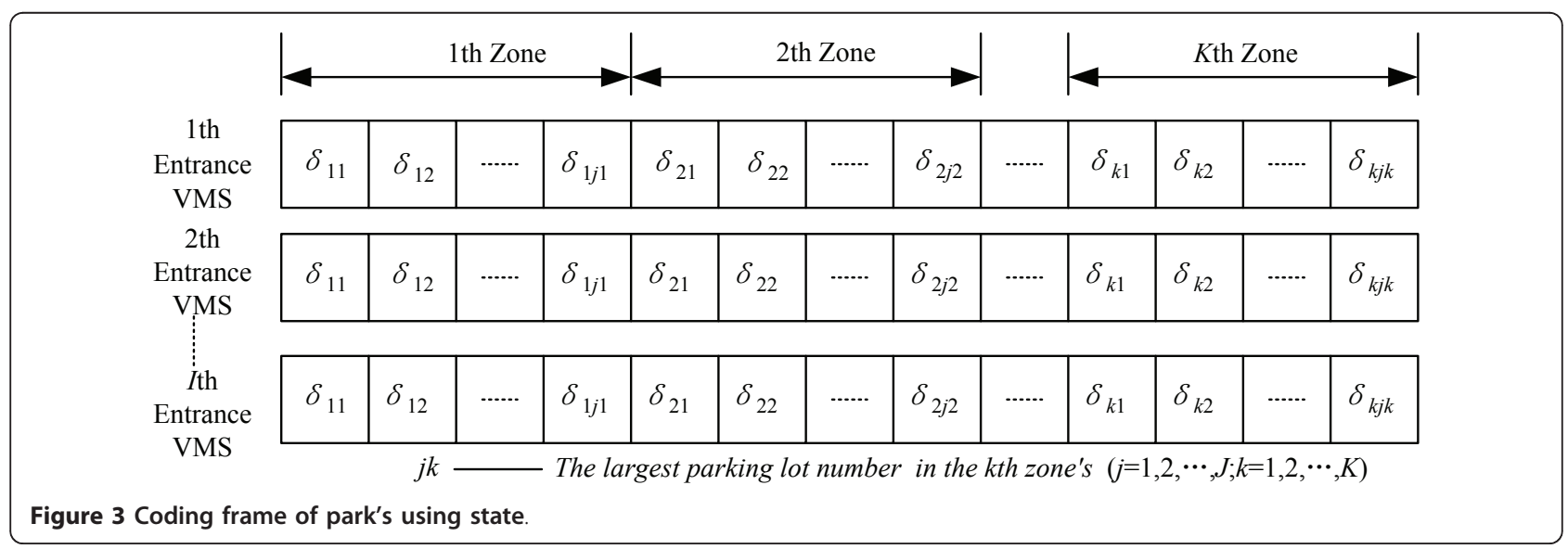




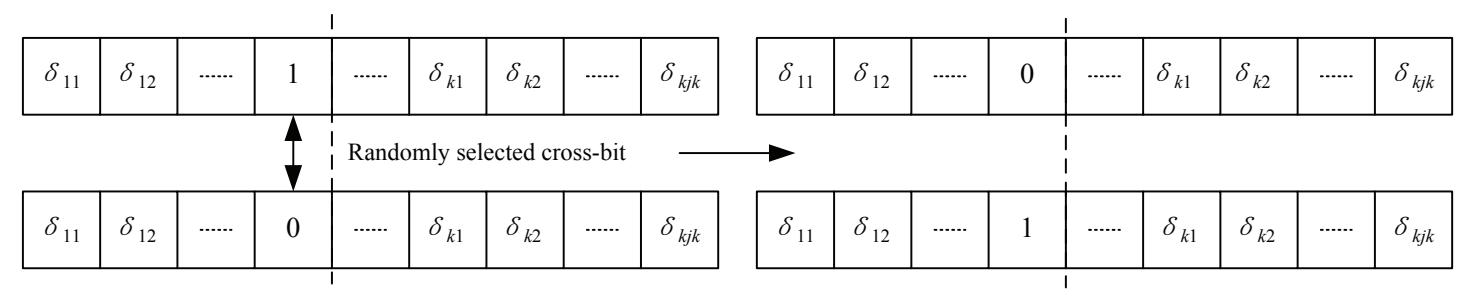

Figure 4 Binary system coding cross operation.

For mutation, the larger $P_{\mathrm{m}}$ is, the more possible the good individuals are produced. However, algorithm convergence would be ineffective; if $P_{\mathrm{m}}$ is too small, then the variation ability would be bad, which could make the initial population become a same population too early. The value empirically in the suggested range can be selected.

6. Termination: Take the mutated population into step (3) to calculate out the minimum fitness of total travel time in certain zone. Whether the algorithm should be terminated is determined by the principles set above. There are two conditions in which the algorithm can be terminated.

For the fixed $m$, if there exist an individual $\delta_{j}(1<j \leq$ $\mathrm{H})$ which makes $\min (T)<\min \left(T_{\text {ini }}\right)$, then make min $\left(T_{\mathrm{ini}}\right)=\min (T)$, repeat the selection, crossover and mutation to conduct the iteration.
The number of offspring has exceeded the minimum times of iteration $M$ set before.

\section{Model application}

\subsection{Example 1}

Most cities in China are on the beginning stage of PGIS. This article takes parts of the urban area of Deqing in Zhejiang Province as one example to simulate PGIS. The sketch map and the division of a certain parking zone are showed in the Figure 5. Through the analysis of the popular car park 1, the effects of the optimized model of PGIS configuration can be tested.

In this example, $l=10 \mathrm{~min}$ and the average parking duration of all the vehicles is $1 \mathrm{~h}$. The parking spaces, with the same parking fee for 3 yuan/h, have the capacity of 100. Take the saturation threshold $\tau_{111}=\tau_{333}=$ $\tau_{444}=80 \%$. Because of the good location, the parking

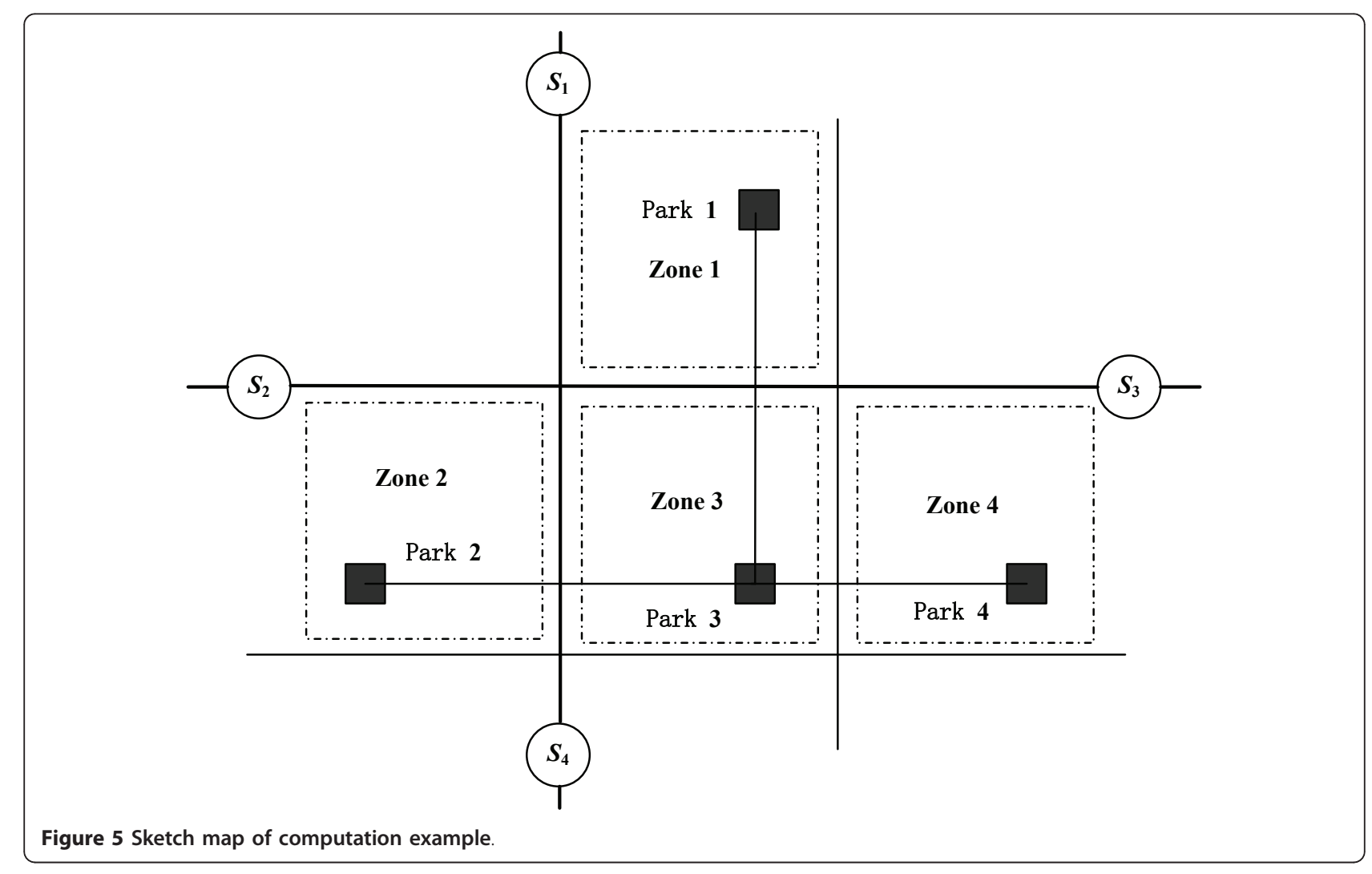


space 1 in zone 1 has the largest attraction for the vehicles, with a saturation of above $90 \%$ in peak period. $q_{i j} \mathrm{~s}$ value can be determined by Table 1 .

Take $I=J=K=4$, then $N=H=2^{4 \times 4}$, which means on the 4 VMSs at the entrance in urban area, there exists $2^{16}$ combinations of status for 4 parking spaces. As the initial population contains the possible maximum combinations, it can guarantee the accuracy. Setting $P_{\mathrm{c}}$ $=0.6, P_{\mathrm{m}}=0.005, M=5000$. The result is shown in Table 2.

Based on the table above, it can be concluded that the total travel time is reduced largely when the proposed PGIS is applied, which indicates that total effect of PGIS is better than the condition without PGIS, as is shown in Figure 6.

Min $T$ appears when there are high $\tau_{111}(95$ to $100 \%)$ and they are above the threshold. In this case, because of the status displayed on the VMS, parts of the drivers do not choose parking space 1 but choose other proper parking spaces, resulting in less vehicles in parking space 1, optimizing the total travel time. After proposed PGIS are applied, under the condition of high saturation of popular parking spaces, the utility of available parking sets can be improved and the parking source can be made full use of.

\subsection{Example 2}

Example 2 is also used to investigate the operational performance of the PGI system for Xiuning City, a regional centre approximately $50 \mathrm{~km}$ south of Huangshan Mountain. The existing PGI system, which was built in 2010, provides availability information for offstreet 4 car parks (Figure 7). On-street parking is not permitted within the city centre.
Traffic count data from peak period as well as landuse pattern information are used to estimate an origin and destination matrix. High volumes are observed entering the city centre from links with PGI signs $S_{1}, S_{2}$, and $S_{4}$. Due to the railway station, high proportion traffic is estimated to have its final destination in zone $\mathrm{Z3}$, with moderate level of demand for zones Z1, Z2, and Z4. All car parks except P3 had approximately 70\% utilization at the time at which the configuration of signs for the next display interval is determined. All car parks in Xiuning City are off-street with the same fee structure for short-term parking. Estimates of in vehicle travel times and walking times are based on the location of the car parks, traffic, and pedestrian links within the city centre (Figure 7). Each choice parker is assumed to have the same parking duration of $1 \mathrm{~h}$.

According to the field survey and computation results, the optimization model is able to identify PGI display configurations that substantially reduce the total travel time. The total travel time is estimated to be 36.6 and $59.8 \mathrm{~h}$ where the utilization threshold was below and above this level, respectively, which lead to a maximum reduction of approximately 41\% (Table 3 ).

\section{Conclusion}

This article described procedures that were developed for investigating the effect of PGI sign boards on parking choice behavior. An optimized model was able to distribute the exceeding parking demand into proper parking spaces. Through guiding the drivers to choose the proper parking spaces instead of popular ones, the total travel time can be reduced. In this model, some simplify assumptions would perhaps overestimate the effect of PGI sign board on parking choice behavior. In particular, if the observers were not assumed to believe

Table 1 Parks' capacity.

\begin{tabular}{|c|c|c|c|c|}
\hline \multirow[t]{2}{*}{ Entrance direction } & \multicolumn{4}{|c|}{ Zoning code } \\
\hline & 1 & 2 & 3 & 4 \\
\hline$S_{1}$ & 80 & 30 & 30 & 30 \\
\hline$S_{2}$ & 80 & 30 & 30 & 30 \\
\hline$S_{3}$ & 80 & 30 & 30 & 30 \\
\hline$S_{4}$ & 80 & 30 & 30 & 30 \\
\hline
\end{tabular}

Table 2 Computation results of park 1.

\begin{tabular}{llllllllllllllllll}
\hline VMS & $\boldsymbol{\delta}_{\mathbf{1}}$ & & & & $\boldsymbol{\delta}_{\mathbf{2}}$ & & & & $\mathbf{\boldsymbol { \delta } _ { 3 }}$ & & & & $\boldsymbol{\delta}_{\mathbf{4}}$ & & & Min $\boldsymbol{T}$ (h) \\
& $\mathbf{1}$ & $\mathbf{2}$ & $\mathbf{3}$ & $\mathbf{4}$ & & $\mathbf{2}$ & $\mathbf{3}$ & $\mathbf{4}$ & $\mathbf{1}$ & $\mathbf{2}$ & $\mathbf{3}$ & $\mathbf{4}$ & $\mathbf{1}$ & $\mathbf{2}$ & $\mathbf{3}$ & $\mathbf{4}$ & 43.74 \\
\hline No PGIS & - & & & & - & & & & - & & & & - & & & \\
Proposed PGIS & & & & & & & & & & & & & & & & \\
$\tau_{111}<95 \%$ & $E$ & $F$ & $F$ & $E$ & $F$ & $F$ & $E$ & $F$ & $F$ & $E$ & $E$ & $F$ & $F$ & $F$ & $E$ & $F$ & 23.44 \\
$\tau_{111} \geq 95 \%$ & $E$ & $F$ & $F$ & $E$ & $E$ & $F$ & $F$ & $E$ & $F$ & $E$ & $E$ & $F$ & $E$ & $F$ & $E$ & $E$ & 22.13 \\
\hline
\end{tabular}




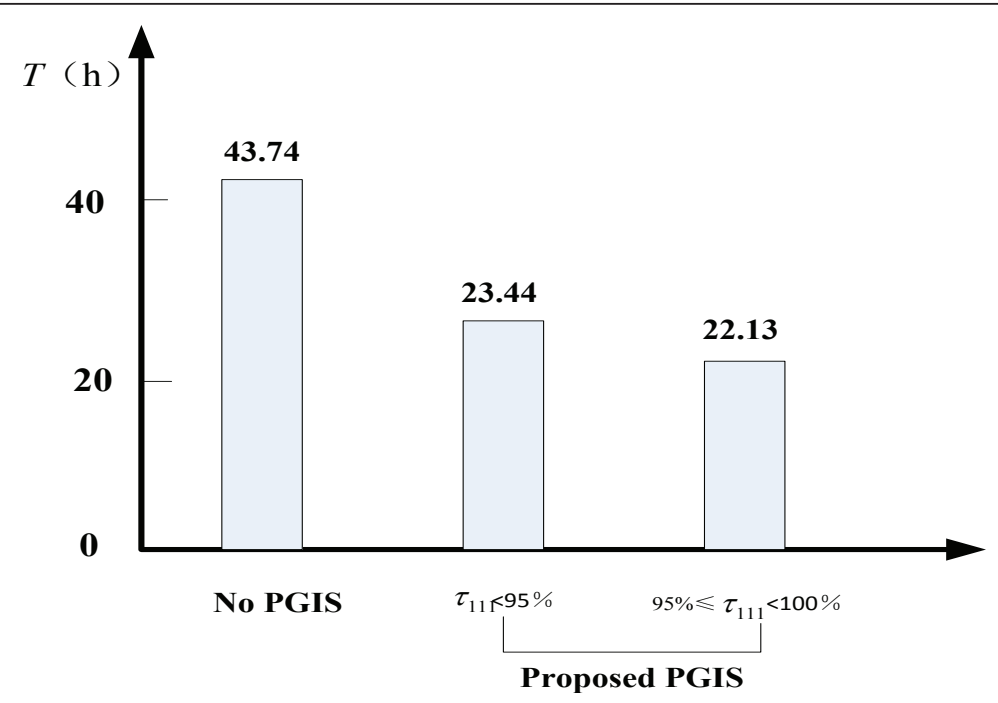

Figure 6 The total time T comparisons of no PGIS and proposed PGIS.

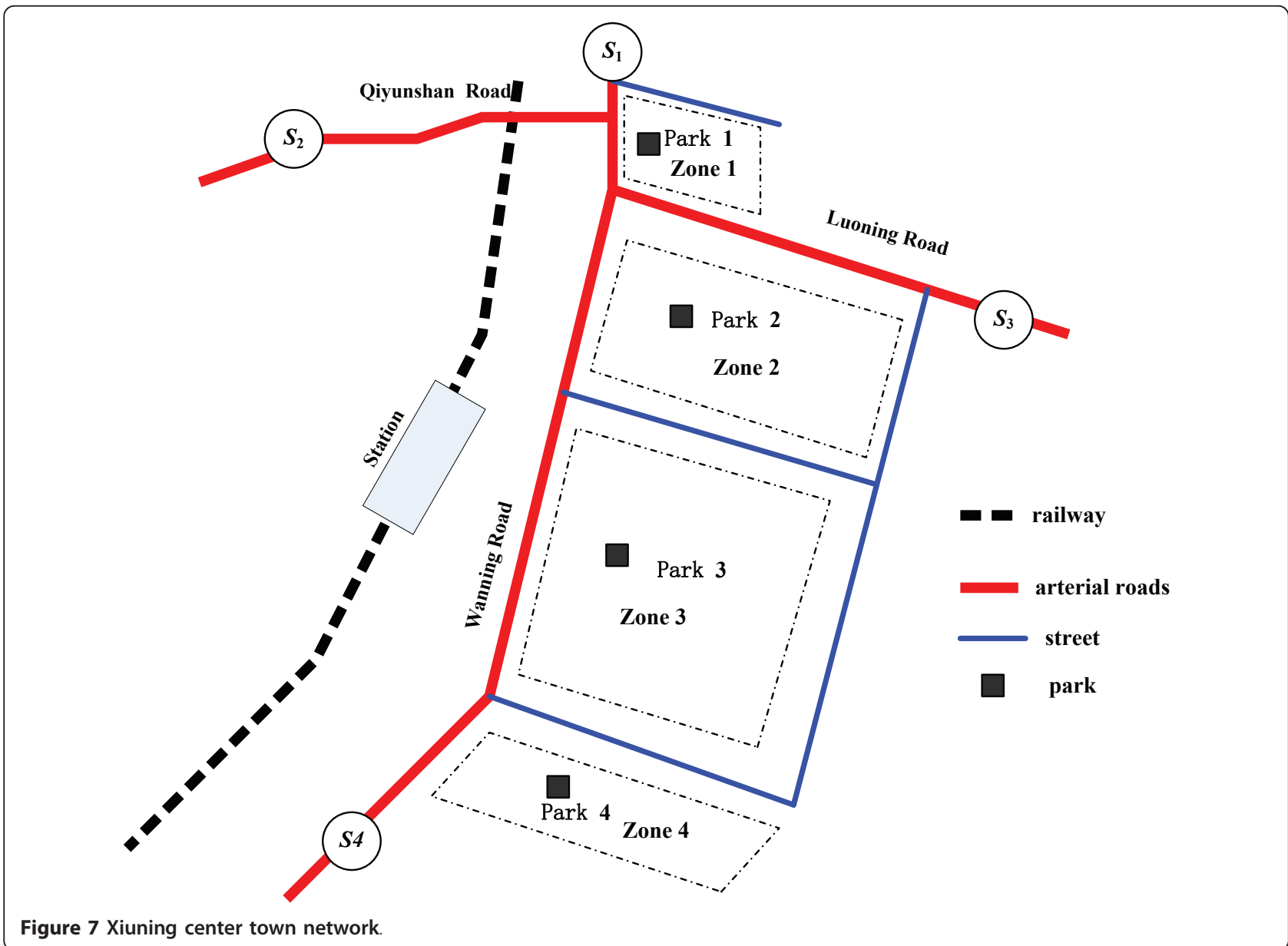


Table 3 Computation results of park 3.

\begin{tabular}{ll}
\hline VMS & Min. $\boldsymbol{T}(\mathbf{h})$ \\
\hline No PGIS & 62.4 \\
Proposed PGIS & \\
$\tau_{111}<95 \%$ & 36.6 \\
$\tau_{111} \geq 95 \%$ & 59.8 \\
\hline
\end{tabular}

the PGI sign board, the potential of PGIS to influence and manage traffic movement as well as parking choices would be reduced. A similar reduced effect would occur if any illegal parking was considered.

\section{List of abbreviations}

Al: artificial intelligent; GA: genetic algorithm; ITS: intelligent transportation systems; PGI: parking guidance and information; PGIS: parking guidance information system; SGA: standard genetic algorithm; VMS: variable message signs.

\section{Acknowledgments}

The work is supported by the National Natural Science Foundation of China (no.50908205) and the National High-tech Research and Development Program (863 Program) (no.2011AA110304).

\section{Author details}

'Department of Civil Engineering, Zhejiang University, Hangzhou, 310058 China ${ }^{2}$ Department of Civil Engineering and Engineering Mechanics, University of Arizona, Tucson, AZ 85721, USA

\section{Competing interests}

The authors declare that they have no competing interests.

Received: 7 March 2011 Accepted: 19 September 2011 Published: 19 September 2011

\section{References}

1. Y Asakura, M Kashiwadani, Evaluation of availability information service by parking choice simulation model, in Proceedings of the International Conference on Advanced Technologies in Transportation and Traffic Management, Centre for Transportation Studies, Nanyang Technological University, Singapore, pp. 335-342 (1994)

2. J Polak, I Hilton, K Axhausen, W Young, Parking guidance and information systems: performance and capability. Traffic Eng Control. 31(10), 519-524 (1990)

3. R Thompson, A Richardson, A parking search model. Transport Res A. 32, 159-170 (1998)

4. F Caicedo, Gestión de aparcamientos subterráneos, Edicions (UPC, Barcelona, 2005)

5. J-H Lee, J Chen, T Ernst, Securing mobile network prefix provisioning for NEMO based vehicular networks. Math Comput Modell (2011) (in press)

6. H Choi, I Kim, J Yoo, Secure and efficient protocol for vehicular ad hoc network with privacy preservation. EURASIP J Wirel Commun Netw 2011, $1-14(2011)$

7. J Chinrungrueng, U Sunantachaikul, S Triamlumlerd, Smart parking: an application of optical wireless sensor network, in Proceedings of the the 2007 International Symposium on Applications and the Internet Workshops (SAINTW'07), Hiroshima, Japan 66-69 (January 2007)

8. $R L u, X$ Lin, $H$ Zhu, $X$ Shen, SPARK: a new VANET-based smart parking scheme for large parking lots, in The 28th IEEE International Conference on Computer Communications (INFOCOM 2009), Rio de Janeiro, Brazil), pp. 19-25 (April 2009)

9. $Y$ Bi, L Sun, H Zhu, T Yan, Z Luo, A parking management system based on wireless sensor network. Acta Automat Sin. 32(6), 968-977 (2006)

10. S Lee, Y Dukhee, G Amitabha, Intelligent parking lot application usingwireless sensor networks, in Proceedings of CTS, Irvine, CA, USA 49-58 (May 2008)
11. Z Mei, Y Xiang, J Chen, W Wang, Optimizing model of curb parking pricing based on parking choice behavior. J Transport Syst Eng Inf Technol. 10, 99-104 (2010)

12. B Zhang, K Yan, X Zhou, Optimization of selecting PGI sign locations based on parking guidance behavior survey, in International Conference on Transportation Engineering, Proceedings of the First International Conference, Chengdu, China 34-39 (July 2007)

13. R Thompson, K Takada, S Kobayakawa, Optimization of parking guidance and information systems display configurations. Transport Res C. 9, 169-85 (2001)

14. H Yan, $X$ Yang, B Yan, Parking choice model study for special events. China J Highway Transport. 18, 90-93 (2005)

15. F Caicedo, The use of space availability information in PARC systems to reduce search times in parking facilities. Transport Res C. 17, 56-68 (2009). doi:10.1016/j.trc.2008.07.001

16. D Tsamboulas, Parking fare thresholds: a policy tool. Transport Policy. 8, 115-124 (2001). doi:10.1016/S0967-070X(00)00040-8

17. D Shoup, The High Cost of Free Parking (American Planning Association, Chicago, 2005)

18. W Marshall, N Garrick, Parking at mixed-use centers in small cities. Transportation Research Record 164-171 (2006)

19. J Oppenlander, Optimal location and sizing of parking facilities. ITE Compendium of Technical Papers 1, 4-6 (1988)

20. D Shoup, The trouble with minimum parking requirements. Transport Res A. 33, 549-574 (1999)

21. T Rye, K Hunton, $\mathrm{S}$ Ison, N Kocak, The role of market research and consultation in developing parking policy. Transport Policy. 15, 387-394 (2008). doi:10.1016/j.tranpol.2008.12.005

22. M Zhou, S Sun, The Theory and Application Of Genetic Algorithm (National Defence and Industry Press, Beijing, 2009)

23. S Clement, J Anderson, Traffic signal timing determination, in Proceedings of the Second International Conference on Genetic Algorithms in Engineering Systems: Innovations and Applications, Conf. Publ. No. 446, IEE, London, UK 63-68 (1997)

doi:10.1186/1687-1499-2011-104

Cite this article as: Mei and Tian: Optimized combination model and algorithm of parking guidance information configuration. EURASIP Journal on Wireless Communications and Networking 2011 2011:104.

\section{Submit your manuscript to a SpringerOpen ${ }^{\circ}$ journal and benefit from:}

- Convenient online submission

- Rigorous peer review

- Immediate publication on acceptance

- Open access: articles freely available online

- High visibility within the field

- Retaining the copyright to your article

Submit your next manuscript at $\gg$ springeropen.com 